\title{
Statistical analysis and optimal design of polymer inclusion membrane for water treatment by $\mathrm{Co}(\mathrm{II})$ removal
}

\author{
Mohammad Shirzad ${ }^{a}$, Mohsen Karimi ${ }^{\mathrm{b}, \mathrm{c}, *}$ \\ ${ }^{a}$ School of Chemical Engineering, College of Engineering, University of Tehran, P.O. Box 11365-4563, Enghelab, Tehran, Iran, \\ Tel.+98 9128026906; email: mdshirzad@gmail.com \\ ${ }^{b}$ Laboratory of Separation and Reaction Engineering (LSRE), Associate Laboratory (LSRE/LCM), Department of Chemical Engineering, \\ Faculty of Engineering, University of Porto, Rua Dr. Roberto Frias, S/N, 4099-002, Porto, Portugal, Tel. +351 934070714 ; \\ AQ1 Fax: +351 225081674; email: mohsen.karimi@fe.up.pt \\ ${ }^{c}$ Grupo de Processos e Produtos Sustentáveis, Centro de Investigação de Montanha (CIMO), 5300-253 Bragança, Portugal
}

Received 1 April 2019; Accepted 22 November 2019

\begin{abstract}
A B S T R A C T
Recently, there is a huge volume of polluted wastewater released from the industries, which adversely affects the environment and human health. As a result, finding a simple, inexpensive, and efficient strategy for water purification is one of the major concerns of researchers. In this study, based on the scope of heavy metals removal from the polluted water, the polymer inclusion membrane has been employed for $\mathrm{Co}$ (II) removal. In this way, the main separation parameters in the membrane structure and aqueous phases including carrier percentage, percentage of plasticizer, $\mathrm{pH}$ of source phase, and receiving phase acid concentration have been considered at the room temperature and atmospheric pressure, simultaneously, by applying the response surface methodology. The range of considered parameters varied between 5 and $35 \%$ wt (total weight of the reference membrane), $40-70 \%$ wt (total weight of the reference membrane), $2.5-6.5$, and $0.5-2.5 \mathrm{~mol} \mathrm{~L}^{-1}$ for the carrier percentage, percentage of plasticizer, $\mathrm{pH}$ of the source phase, and receiving phase acid concentration, respectively. The statistical analysis of experimental tests showed an admissible agreement between these values and model outputs by developing acceptable results for Adj- $R^{2}(0.9978)$ and $p$-value $(p<0.0001)$. Also, the ion removal has been optimized by maximizing the removal factor at a constant time of $24 \mathrm{~h}\left(\% \mathrm{RF}_{\max }=73.25 \%\right)$ to achieve the optimum quantities of considered parameters. A test in the optimal operational conditions with the removal factor of $73.99 \%$ verified the reliability and accuracy of the proposed model. Finally, the interaction coefficients between the considered variables are completely analyzed to have a better grasp about the polymer inclusion membranes.
\end{abstract}

Keywords: Polymer inclusion membrane; Cobalt(II) separation; Response surface methodology (RSM); Central composite design; Optimization

\section{Introduction}

Cobalt elements are naturally available in certain ores of the Earth's crust. This heavy metal has several main applications in the various industries including catalyst synthesis [1], alloys, steels, etc. [2]. While a trace quantity of this metal is essential to the human life (i.e., it can be found in vitamin $B_{12}$ ), the critical dose of $\mathrm{Co}(\mathrm{II})$ ion existing in the effluents and wastes of many industries such as battery recharging, paint and pigment technologies, metal plating, and nuclear power plants is a major concern for advocates of the environment $[3,4]$. It should be considered that the contaminated water with heavy metals is highly dangerous for drinking and also other human usages. For example, a

* Corresponding author. 
higher quantity of $\mathrm{Co}(\mathrm{II})$ in the human body can contribute to many diseases including asthma, diarrhea, lung irritations, pneumonia, vomiting, cancer and gene mutation [5].

\subsection{Polymer inclusion membrane}

There are several techniques to remove the cobalt ions from wastewater [6] including adsorption [7-9], solvent extraction [10,11], liquid membranes (i.e., SLM) [12] and polymer inclusion membranes (PIMs) [6]. PIMs as a simple technique for preparation $[13,14]$, possess high stability, selectivity and efficiency, as well as they can be easily designed based on the nature of heavy metals [15]. On the other hand, a high percentage of extractant is not required in this technique, which introduces this strategy as an environmentally green method [16]. Thus, these features nominate the PIM as an interesting separation approach to remove the cobalt ion from the contaminated water, efficiently.

Generally, PIMs have been constituted by three main components including the polymer [17], the plasticizer and the carrier [18]. The PIMs are basically similar to the conventional supported liquid membranes (SLMs). There is a substance as a carrier in both separation methods that reacts with the ions and facilitates the ion transport [19]. The membrane is a flexible thin polymeric film, which is plasticized and activated by a plasticizer and the carrier, respectively $[19,20]$. In this work, CTA (cellulose triacetate) was employed as the base polymer, DOA (dioctyl adipate) as the plasticizer, and DNNSA (dinonylnaphthalene sulfonic acid) as the carrier in the PIM structure. Based on Le Chatelier's principle, the free carrier tends to react with the cobalt ions in the less acidic aqueous phase (source/membrane interface), and the high acidic aqueous phase (membrane/receiving interface) leads to the reverse reaction and liberates the free $\mathrm{Co}(\mathrm{II})$ ion, according to the following equilibrium reaction [21]:

$\left(\mathrm{Co}^{2+}\right)_{\mathrm{aq}}+2(\mathrm{HA})_{m} \rightleftarrows\left(\mathrm{CoA}_{2}\right)_{m}+\left(2 \mathrm{H}^{+}\right)_{\mathrm{aq}}$

where 'aq' and ' $m$ ' subscripts display the aqueous and membrane phases, respectively, and (HA) and $\left(\mathrm{CoA}_{2}\right)$ are DNNSA and carrier/ion complex, respectively.

As shown in Fig. 1, cobalt(II) ion in the aqueous source phase reacts with the carrier at the membrane/source interface and forms the complex [22]. The complex diffuses through the membrane phase to the membrane/receiving interface [21], where by reversing the described reaction, the $\mathrm{Co}(\mathrm{II})$ ion is stripped in the receiving phase and the free carrier is released in the membrane phase [23], initiating a new separation cycle [24]. This cycle is conducted till all the $\mathrm{Co}(\mathrm{II})$ ions are extracted, entirely [22].

It is worth mentioning that the excess amount of the acidity in the receiving phase compared with the source phase is the mass transfer driving force, which has been reported in several studies $[21,23,25]$.

\subsection{Response surface methodology}

The response surface methodology (RSM) is a statistical strategy accompanied with mathematical methods to analyze and optimize the dependent variables (responses) in the considered range of the independent variables (factors) [26]. In this way, diverse regression analyses are applied to evaluate the effects of the independent parameters on the developed response. This technique employs the experimental data and fits a mathematical equation to predict the

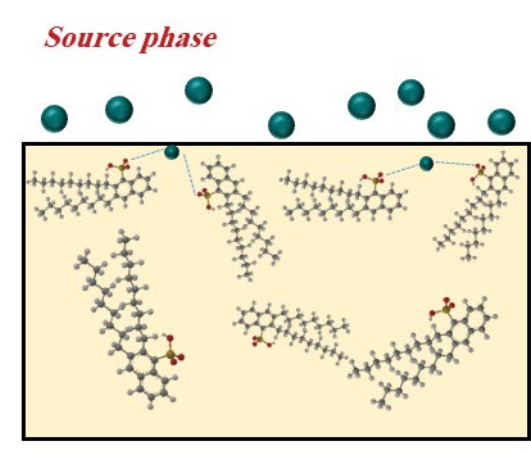

Receiving phase

Reaction with DNNSA and converting to complex

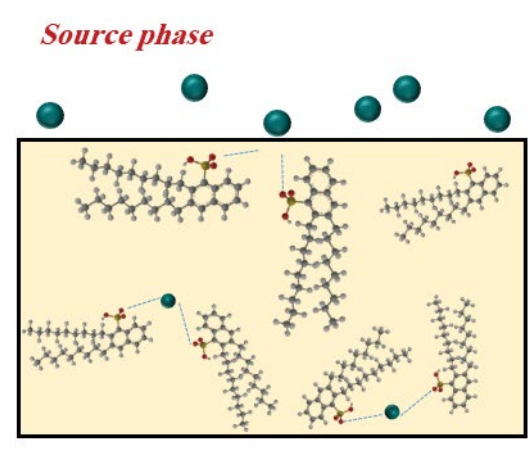

Receiving phase

Complex diffusion

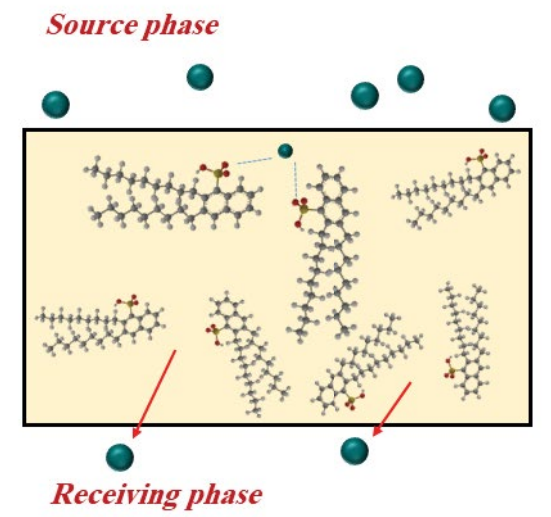

Co(II) ion stripping

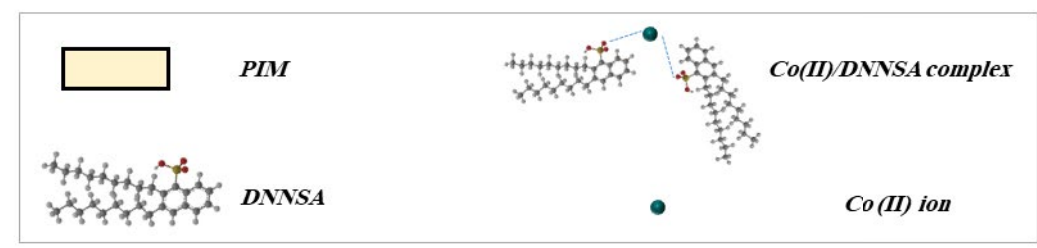

Fig. 1. Co(II) transport through the PIM. 
response of the desired set of data [27]. The investigation of interaction effects, between the independent variables of the process is one of the major benefits of this approach [26]. Also, reducing the number of experiments, high accuracy, and its flexibility are the other advantages of this method. This approach is illustrated in Fig. 2, schematically. As observed, the factors can affect the response, directly, or by their internal interactions. It is worth mentioning that among the different RSM techniques, central composite design (CCD) has been introduced as a user friendly method with high accuracy, which is considered as the most frequently used strategy for Design Experiments [28].

To the best of our knowledge, there is no study which considered the RSM technique to optimize the concentrations of constituents of the PIM or ion extraction parameters. While this strategy (RSM) has already been applied in the adsorption process for water purification by heavy metal removal and optimizing the adsorption parameters [29,30].

\subsection{Objective}

In this study, based on the scope of the water purification and removal of heavy metals from contaminated water, PIM has been considered because of its high stability and significant selectivity toward a special solute, as well as non-tendency to fouling [31]. Then, for the first time, the response surface methodology has been applied on the PIM to develop a general approach. In this way, the main parameters in the membrane structure and aqueous phases have been evaluated, simultaneously. Also, the ion removal and water purification have been optimized by maximizing the removal factor at the specified time to achieve the optimum quantities of the considered parameters. In addition, the interaction coefficients between the variables have been completely investigated to have a better grasp about the PIMs.

\section{Materials and methods}

\subsection{Materials}

In this work, the polymer CTA was purchased from Fluka (Germany). The PIM solvent dichloromethane, receiving phase $\mathrm{H}_{2} \mathrm{SO}_{4}$ solution, and the plasticizer DOA were obtained from Merck (Germany). The considered phosphate/citrate buffer for the source phase was prepared in the laboratory by mixing an appropriate percentage of $0.2 \mathrm{M} \mathrm{Na}_{2} \mathrm{HPO}_{4}$ and $0.1 \mathrm{M}$ citric acid, which were supplied by SIGMA-ALDRICH (Germany). The carrier DNNSA and $\mathrm{CoCl}_{2} \cdot 6 \mathrm{H}_{2} \mathrm{O}$ were also prepared from SIGMA-ALDRICH, which is now named as Merck (Germany). It is worth mentioning that all employed solutions were prepared with freshly doubly distilled water (conductivity $\leq 1 \mu \mathrm{s} / \mathrm{cm}$ ) which was prepared in the lab. The name, chemical and structural formula of the considered materials for the membrane preparation are reported in Table 1 [32].

\subsection{PIM preparation procedure}

The required percentage of polymer in $20 \mathrm{~cm}^{3}$ of dichloromethane was dissolved to obtain the base solution of the PIM structure. Another dichloromethane solution, contained an appropriate amount of DNNSA in $15 \mathrm{~cm}^{3}$ of the solvent, was prepared and stirred for $15 \mathrm{~min}$ to get a homogenous solution. In the next step, DOA as a plasticizer was blended into DNNSA solution. The resulting solution was mixed around $10 \mathrm{~min}$ then, the solution was made fully homogenous by ultrasonication technique for $2 \mathrm{~min}$. The obtained solution was blended with the base polymer solution and mixed by the mechanical stirrer for about $60 \mathrm{~min}$. The developed mixed solution was poured into a membrane mold, comprising a $9.0-\mathrm{cm}$ glass ring attached to a glass plate with CTA-dichloromethane glue to allow the solvent to be evaporated overnight, gradually (for $12 \mathrm{~h}$ ). In the last step, the casted membrane was immersed in the cold double distilled water and then, separated from the glass plate by cutting its surroundings [33]. After that, the separated membrane was soaked in the aqueous solution of $0.1 \mathrm{~mol} \mathrm{~L}^{-1} \mathrm{HCl}$ for $12 \mathrm{~h}$. Finally, the PIM was stored in the distilled water for next applications. It is worth mentioning that in this study a reference PIM with $0.1211 \mathrm{~g}$ CTA, $0.3263 \mathrm{~g} \mathrm{DOA}$, and $0.0789 \mathrm{~g}$ DNNSA has been considered. In this way, in all experiments in which the component composition was varying, the DOA and DNNSA quantities in the PIM were calculated according to the total weight of the reference membrane. The prepared PIM for this study in our lab is illustrated in Fig. 3.

\subsection{Experimental apparatus and Co(II) transport experiment}

The employed apparatus for ion transport experiments was a circular section compartment, which consists of two columns by the volume of $80 \mathrm{~mL}$ for each one, and separated by the PIM with a diameter of $31 \mathrm{~mm}\left(0.00075 \mathrm{~m}^{2}\right)$ [15]. These two columns were the source and receiving phases and stirred at $200 \mathrm{rpm}$ by mechanical stirrers. The schematic of this compartment is represented in Fig. 4.

In all experiments, the initial ion concentration in the source phase was maintained at $60 \mathrm{ppm}$, and $\mathrm{pH}$ was varied between 2.5 and 6.5 . The source phase was prepared by dissolving a proper mass of $\mathrm{CoCl}_{2} \cdot 6 \mathrm{H}_{2} \mathrm{O}$ salt in the phosphate/citrate buffer. The receiving phase consisted of $\mathrm{H}_{2} \mathrm{SO}_{4}$ with different concentrations. The membrane structure was varied by changing the carrier and plasticizer percentages, according to the reference membrane (the membrane contained $0.1211 \mathrm{~g}$ CTA, in all experiments). The range of considered parameters (variables) varied between 5 and

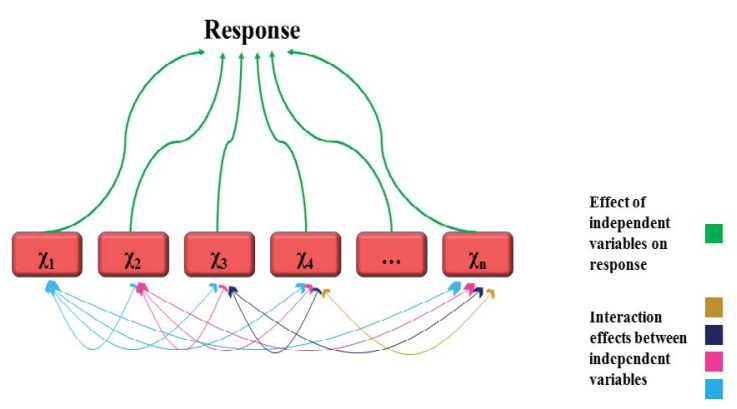

Fig. 2. Effects of independent variables on each other and on the response surface. 
Table 1

Name, chemical, and structural formula of the materials used for the membrane preparation

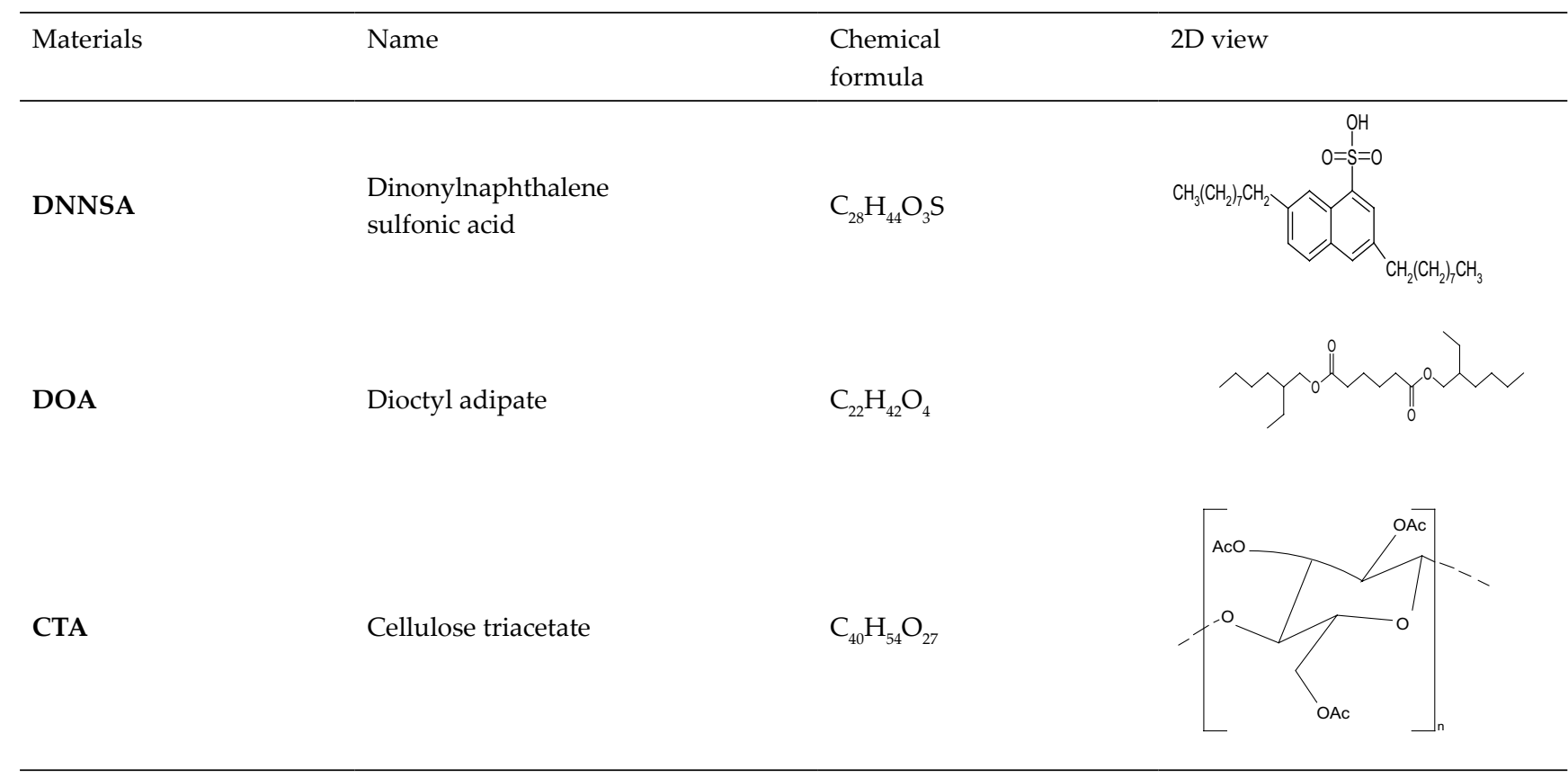

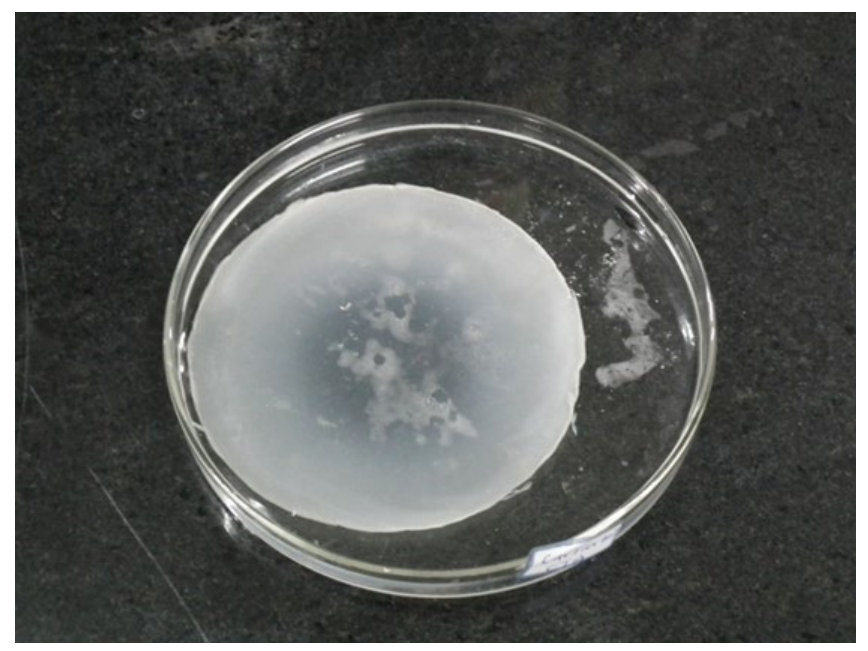

Fig. 3. PIM synthesized in lab.

$35 \%$ wt (of total weight of the reference membrane), 40 and $70 \%$ wt (of total weight of the reference membrane), 2.5 and 6.5 , and 0.5 and $2.5 \mathrm{~mol} \mathrm{~L}^{-1}$ for the carrier percentage, percentage of plasticizer, $\mathrm{pH}$ of source phase, and receiving phase acid concentration, respectively. Also, the temperature was kept constant at the room temperature during the experiments. The removal factor of $\mathrm{Co}(\mathrm{II})$ was applied to analyze and compare the water purification results obtained from different experiments. The removal factor can be calculated by the following equation [34]:

$\mathrm{RF}=\left(\frac{C_{i}-C}{C_{i}}\right) \times 100$

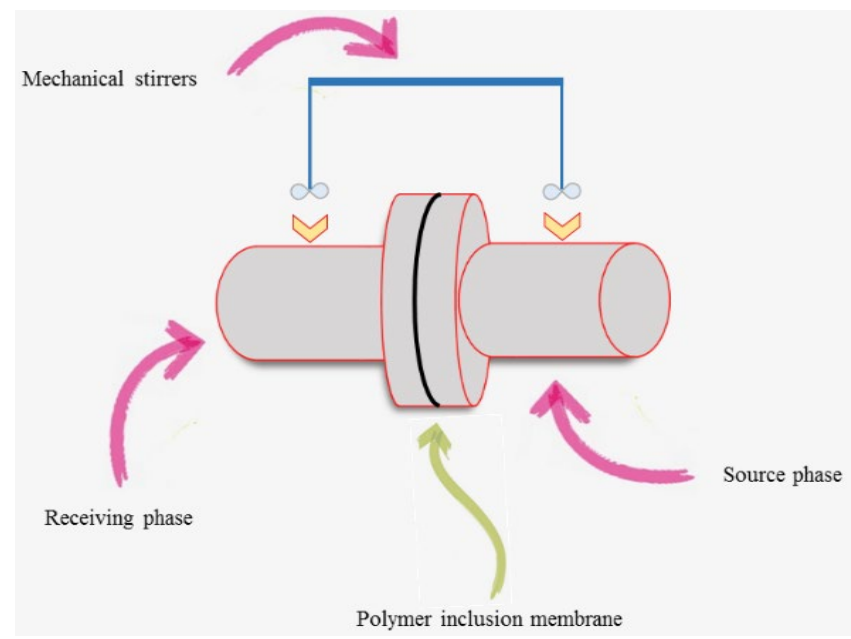

Fig. 4. Schematic of the compartment used for ion transport.

where $C_{i}$ and $C$ are $\operatorname{Co}(\mathrm{II})$ concentrations at the initial and tested times in the source phase, respectively. In this study, samples were taken from the source phase at the particular time intervals via sampling port with a syringe. To evaluate the results of the removal factor, all experiments were conducted in $24 \mathrm{~h}$. Then, the obtained results of RF after $24 \mathrm{~h}$ were considered in the modeling procedure. The samples were analyzed by inductively coupled plasma optical emission spectrometry (ICP-OES) to determine the cobalt content.

\subsection{Central composite design}

The PIM structure and aqueous phase parameters play a crucial role in the efficiency of the membrane extraction and 
if all parameters retain in the optimum values, it contributes to the reduction of the full ion extraction period. Hence, the optimization of the extraction parameters has been a significant part of purification studies. In this work, based on the superior abilities of the CCD strategy, it has been selected between different methods of response surface methodology (RSM) to designing, modeling and optimization of PIM for water treatment. The RSM is a combination of statistical and mathematical methods, which investigates the effects and interactions of independent variables of process in different levels. RSM, also as a method of optimization, reduces the experimental runs and supplies a group of valid data, which can be employed to develop a general model. On the other hand, the other optimization methods including full factorial design and one-variable-at-time are more superficial and much slower techniques than the RSM [35]. In addition, among different designing tools of the RSM, the $\mathrm{CCD}$ as the most popular one, requires lower experimental values for statistical analysis and mathematical modeling $[36,37]$. These benefits have introduced the CCD as an excellent strategy in different steady-state and dynamic processes [37].

A set of CCD runs include three terms: $2 n$ axial runs, which give the ability of curvature description of the model, $2^{n}$ factorial runs, and $n$ central runs to have an ability for measuring the reproducibility and revealing a model for lack of fit. $n$ and $n_{c}$ represent the independent variable number and number of central points, respectively [29]. Thus, the total runs of the CCD can be calculated by:

Total number of required experiments $=2 n+2^{n}+n_{c}$

In this work, total number of experiments consist of 30 runs, which include 8 axial points, 16 factorial points and 6 replicate center runs $[38,39]$.

The obtained CCD model was applied through the Design-Expert software (version 7.0) to optimize the Co(II) extraction from aqueous solutions by PIM. To the best of our knowledge, this study is the first one, which has considered the CCD technique to investigate and optimize the heavy metal removal by PIM.

The first step to design a CCD model is finding the main independent variables, as factors of the model, which are defined as the dependent variable(s). To this end, the carrier percentage $\left(x_{1}\right)$, the plasticizer percentage $\left(x_{2}\right), \mathrm{pH}$ of source phase $\left(x_{3}\right)$, and the receiving phase acid concentration $\left(x_{4}\right)$ were considered as the model variables. Also, we supposed the removal factor (RF) as the surface response. Then, a non-linear second order polynomial equation was applied to evaluate the behavior of considered variables. The model can be described by Eq. (4):

$$
\begin{aligned}
Y=\beta_{0}+ & \sum_{i=1}^{4} \beta_{i} \cdot \chi_{i}+\sum_{j=1}^{4} \beta_{j j} \times \chi_{i} \times \chi_{j}+\sum_{k=2}^{4} \beta_{1 k} \times \chi_{1} \times \chi_{k}+ \\
& \sum_{m=3}^{4} \beta_{2 m} \times \chi_{2} \times \chi_{m}+\beta_{34} \times \chi_{3} \times \chi_{4}+\varepsilon
\end{aligned}
$$

here $Y$ is the response surface (RF). $x_{1}, x_{2^{\prime}}, x_{3^{\prime}}$ and $x_{4}$ represent the independent variables, also $\beta_{0}$ is the constant term, $\beta_{i}$ is the linear effect of the $i$ th factor coefficient, $\beta_{i j}$ is the coefficient of the quadratic parameter, $\beta_{1 k^{\prime}} \beta_{2 m^{\prime}}$ and $\beta_{34}$ are the coefficients of the interaction parameters and $\varepsilon$ is the observed error in the response [26,35]. In this way, each independent variable has three levels coded as $-1,0$, and +1 . The required runs to design the three-level face-centered CCD matrix are reported in Table 2, also the independent variables and the levels are shown in Table 3.

In the next step, by employing the least square method and multiple regression analysis, the mentioned coefficients are computed and it contributes to a general correlation. In this way, the regression analysis of variance (ANOVA) of the designed model is performed by the statistical evaluation of results to develop a significant model for the separation process [40]. The $p$-value test to $95 \%$ level of confidence was considered to evaluate the significance of model coefficients. $R^{2}$ (regression coefficient) and adjusted $R^{2}$ are two parameters (Eqs. (5) and (6)), which considered to obtain a model with high accuracy. The developed approach is valid when $R^{2}$ and Adj- $R^{2}$ represent a significant regression (close to 1.0), also getting a non-significant lack of fit [39]. Adjusted $R^{2}$ is more reliable than $R^{2}$, because the number of variables is taken into account through Adj- $R^{2}$ calculation. Adj- $R^{2}$ shows the proportion of variability of calculated values of the model, while close values to 1 indicate a model with higher accuracy [26].

The root mean square error (RMSE) and the percentage root mean square error (\%RMSE) (Eqs. (7) and (8)) are other two factors to elucidate the model performance, while their lower values illustrate the higher accuracy [41].

$$
R^{2}=1-\frac{\sum_{i=1}^{n}\left(y_{i}-\hat{y}_{i}\right)^{2}}{\sum_{i=1}^{n}\left(y_{i}-\hat{y}\right)^{2}}
$$

$\operatorname{Adj} R^{2}=1-\frac{\left(1-R^{2}\right) \times(n-1)}{(n-P-1)}$

$\mathrm{RSME}=\sqrt{\frac{\sum_{i=1}^{n}\left(y_{i}-\hat{y}_{i}\right)^{2}}{n-P}}$

$\%$ RSME $=$ RSME $\times \frac{100 \times n}{\sum_{i=1}^{n} y_{i}}$

where $y_{i^{\prime}} \hat{y}_{i^{\prime}}$ and $\bar{y}$ represent experimental data, predicted value, and the average of experimental data, respectively. Also, $n$ is the number of experiments and $P$ is the number of predictors [39].

\section{Results and discussion}

\subsection{Model fitting and statistical analysis}

In order to evaluate the main variables in the PIM and their interactions on the RF, an RSM model was developed; which it contributed to a correlation to estimate the cobalt removal from the aqueous solutions. At the first step, four independent variables were considered simultaneously, 
Table 2

Central composite design with \%RF and time as responses

\begin{tabular}{|c|c|c|c|c|c|}
\hline \multirow{2}{*}{$\begin{array}{l}\text { Run } \\
\text { no. }\end{array}$} & \multicolumn{4}{|c|}{ Variables $^{a}$} & \multirow{2}{*}{$\begin{array}{l}\text { Response } \\
\text { Removal factor } \\
\text { (\%) (Observed) }\end{array}$} \\
\hline & $\begin{array}{l}\text { Carrier percentage } \\
(\% w t)\end{array}$ & $\begin{array}{l}\text { Percentage of plasticizer } \\
(\% w t)\end{array}$ & $\begin{array}{l}\mathrm{pH} \text { of source } \\
\text { phase }\end{array}$ & $\begin{array}{l}\text { Receiving phase acid } \\
\text { concentration }\left(\mathrm{mol} \mathrm{L}^{-1}\right)\end{array}$ & \\
\hline 1 & 5 & 40 & 2.5 & 0.5 & 2.21 \\
\hline 2 & 35 & 55 & 4.5 & 1.5 & 30.5 \\
\hline 3 & 20 & 55 & 4.5 & 1.5 & 68.83 \\
\hline 4 & 20 & 40 & 4.5 & 1.5 & 36.76 \\
\hline 5 & 35 & 70 & 6.5 & 2.5 & 3.59 \\
\hline 6 & 20 & 55 & 4.5 & 1.5 & 67.83 \\
\hline 7 & 35 & 40 & 6.5 & 0.5 & 3.75 \\
\hline 8 & 35 & 40 & 2.5 & 2.5 & 13.59 \\
\hline 9 & 35 & 40 & 2.5 & 0.5 & 7.5 \\
\hline 10 & 20 & 55 & 4.5 & 2.5 & 68.99 \\
\hline 11 & 5 & 40 & 6.5 & 2.5 & 2.37 \\
\hline 12 & 5 & 70 & 6.5 & 0.5 & 0.95 \\
\hline 13 & 35 & 70 & 2.5 & 0.5 & 2.88 \\
\hline 14 & 20 & 55 & 4.5 & 1.5 & 66.83 \\
\hline 15 & 35 & 40 & 6.5 & 2.5 & 7.85 \\
\hline 16 & 5 & 40 & 2.5 & 2.5 & 4.89 \\
\hline 17 & 20 & 55 & 4.5 & 0.5 & 47.22 \\
\hline 18 & 35 & 70 & 6.5 & 0.5 & 2.05 \\
\hline 19 & 5 & 55 & 4.5 & 1.5 & 14.95 \\
\hline 20 & 20 & 55 & 6.5 & 1.5 & 42.32 \\
\hline 21 & 20 & 55 & 4.5 & 1.5 & 65.83 \\
\hline 22 & 20 & 55 & 2.5 & 1.5 & 60.46 \\
\hline 23 & 20 & 55 & 4.5 & 1.5 & 64.83 \\
\hline 24 & 5 & 70 & 2.5 & 2.5 & 2.39 \\
\hline 25 & 5 & 70 & 2.5 & 0.5 & 1.41 \\
\hline 26 & 5 & 40 & 6.5 & 0.5 & 1.36 \\
\hline 27 & 20 & 55 & 4.5 & 1.5 & 63.83 \\
\hline 28 & 35 & 70 & 2.5 & 2.5 & 6.72 \\
\hline 29 & 20 & 70 & 4.5 & 1.5 & 20.10 \\
\hline 30 & 5 & 70 & 6.5 & 2.5 & 1.49 \\
\hline
\end{tabular}

${ }^{a}$ The percentages of carrier and plasticizer have been considered based on the reference membrane $(0.1211 \mathrm{~g}$ CTA, $0.3263 \mathrm{~g}$ DOA, and $0.0789 \mathrm{~g}$ DNNSA). The reference membrane total weight was $0.5263 \mathrm{~g}$, which was the considered reference for calculation of carrier and plasticizer percentage.

Table 3

Independent variables and the levels

\begin{tabular}{llll}
\hline \multirow{2}{*}{ Variables } & \multicolumn{2}{c}{ Levels } \\
\cline { 2 - 4 } & Lower value $(-1)$ & Center point $(0)$ & Upper value $(+1)$ \\
\hline$\chi_{1}:$ DNNS $(\% w t)$ & 5 & 20 & 35 \\
$\chi_{2}:$ DOA $(\% w t)$ & 40 & 55 & 70 \\
$\chi_{3}: \mathrm{pH}$ & 2.5 & 4.5 & 6.5 \\
$\chi_{4}:$ Receiving phase acid concentration $\left(\mathrm{mol} \mathrm{L}^{-1}\right)$ & 0.5 & 1.5 & 2.5 \\
\hline
\end{tabular}

then, the developed responses were investigated by the RSM. In this way, all experiments (30 runs) were performed based on the CCD order, and conducted during $24 \mathrm{~h}$. The obtained results of \%RF vs. time, for four different instance conditions are illustrated in Fig. 5. Then, the experimental results based on the main independent factors were fitted with quadratic models. After that, the multiple regression analysis and the evaluation of the fitness of the model by ANOVA were performed to determine the lackof-fit and the statistical analysis of the system. To this goal, 


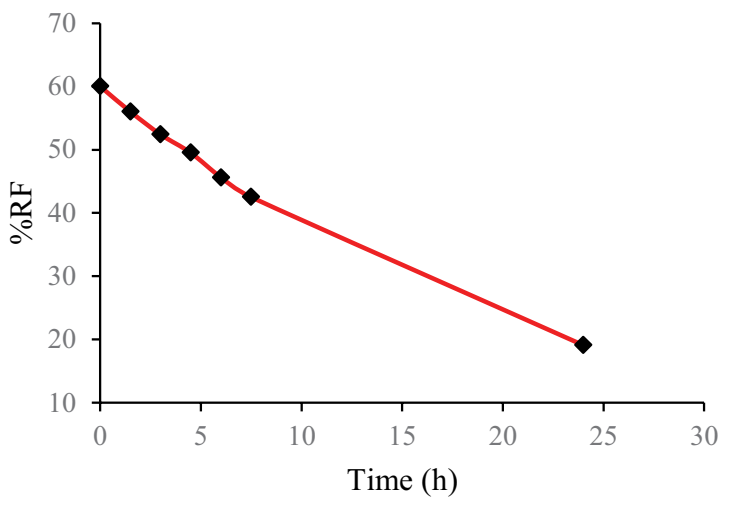

(a)

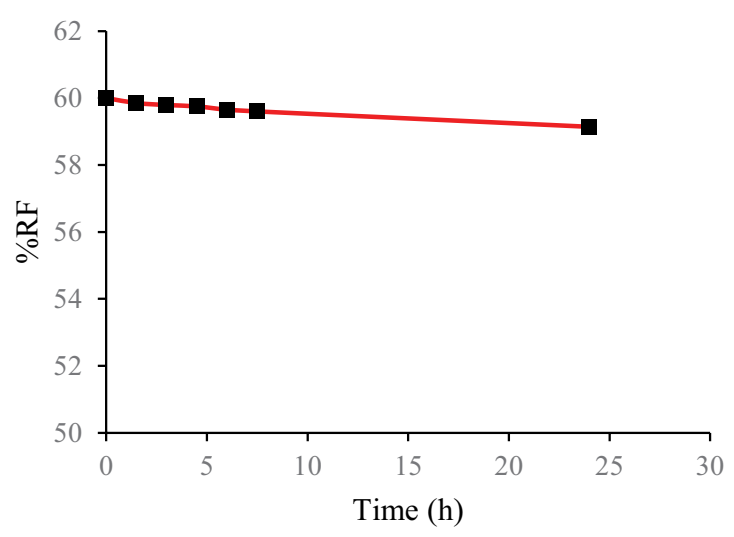

(c)

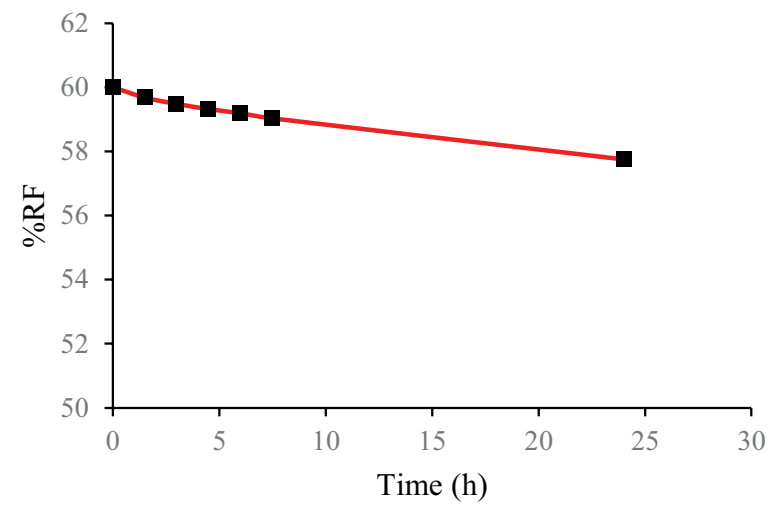

(b)

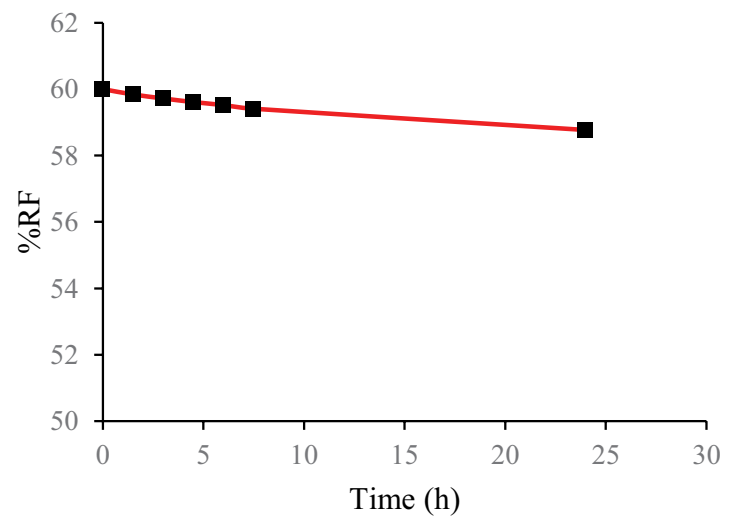

(d)

Fig. 5. Experimental results of PIM tests in four different conditions for instance ((a) DNNS: 20\%wt, DOA: $55 \%$ wt, pH of source phase: 4.5, and $\mathrm{H}_{2} \mathrm{SO}_{4}$ concentration in receiving phase: $1.5 \mathrm{~mol} \mathrm{~L}^{-1}$; (b) DNNS: $35 \% \mathrm{wt}$, DOA: $40 \% \mathrm{wt}, \mathrm{pH}$ of source phase: 6.5 , and $\mathrm{H}_{2} \mathrm{SO}_{4}$ concentration in receiving phase: $0.5 \mathrm{~mol} \mathrm{~L}^{-1}$; (c) DNNS: $5 \% \mathrm{wt}$, DOA: $70 \% \mathrm{wt}$, pH of source phase: 2.5 , and $\mathrm{H}_{2} \mathrm{SO}_{4} \mathrm{concentration} \mathrm{in}_{4}$ receiving phase: $0.5 \mathrm{~mol} \mathrm{~L}^{-1}$; (d) DNNS: $35 \% \mathrm{wt}$, DOA: $70 \% \mathrm{wt}$, $\mathrm{pH}$ of source phase: 6.5 , and $\mathrm{H}_{2} \mathrm{SO}_{4}$ concentration in receiving phase: $\left.0.5 \mathrm{~mol} \mathrm{~L}^{-1}\right)$.

the initial models were analyzed and tested for $p$-value, standard deviation, $R^{2}$, predicted determination coefficient (Pred- $\left.R^{2}\right)$, adjusted $R^{2}$ (Adj- $\left.R^{2}\right)$ and lack-of-fit. Lastly, the final models were derived with the acceptable accuracies, by determining the insignificant parameters and the interactions in the process. The results of ANOVA for removal factor have been reported in Table 4. As can be observed, the lack-of-fit is significant, which is not promising for RSM strategy. Furthermore, all $p$-values except $A^{2}$ and $B^{2}$ were greater than 0.05 , which indicate that they have no significant effects on the removal factor. Also, Fig. 6 illustrates that some predicted values have low accuracy compared with the experimental data. According to Fig. 6, the predicted vs. actual values were so far from the $y=x$ line. Consequently, the model could not properly cover the experimental data and represent a comprehensive model to predict other required responses.

In this study, the maximum to minimum ratio of removal factor data was 72.62 , which a ratio greater than 10 proves that transfer function can improve the reliability of the model, according to Box-Cox plot [42]. Consequently, the model requires a modification, to be considered as a general model. To this end, the power transformation was employed to develop a more reliable and accurate model that decreases the difference between the actual and predicted responses. Thus, the power transformation was employed for response transformation and the value of 0.18 was obtained for $\lambda$ (Lambda). This value was extracted from the Box-Cox plot of the power transforms. The Box-Cox plot is presented in Fig. 7. As can be observed, the selected value is completely equal with recommended quantity by Box-Cox plot [42], and it contributes to the modified quadratic equation as final model. Thus, modified quadratic model was selected as the model correlation, which its ANOVA parameters are reported in Table 5 .

As observed in Table 5, the lack of fit of developed model is insignificant, which is desirable. Also, all correlation coefficients are less than 0.05 , consequently they are significant, except $A C, B D$, and $C D$, which were excluded from the quadratic model. The $p$-values of $A B, A D$, and $B C$ indicated the carrier percentage interaction with percentage of plasticizer and receiving phase acid concentration. In addition, the percentage of plasticizer interacted with $\mathrm{pH}$ of source phase [43]. The $p$-values of $A^{2}, B^{2}, C^{2}$, and $D^{2}$, which indicate 
Table 4

ANOVA results for non-transformed model and quadratic equation of Design-Expert 7.0.

\begin{tabular}{|c|c|c|c|c|c|c|}
\hline & \multicolumn{6}{|c|}{$\mathrm{Co}(\mathrm{II})$ removal factor $(\%)$} \\
\hline & $\begin{array}{l}\text { Sum of } \\
\text { squares }\end{array}$ & $\begin{array}{l}\text { Mean } \\
\text { squares }\end{array}$ & $\begin{array}{l}\text { Coded } \\
\text { coefficient }\end{array}$ & $\begin{array}{l}\text { Standard } \\
\text { error }\end{array}$ & $\mathrm{df}$ & $p$-Value \\
\hline Model & $20,745.53$ & $1,481.82$ & 60.38 & 2.47 & 14 & $<0.0001$ \\
\hline$A$-Carrier percentage & 119.66 & 119.66 & 2.58 & 1.87 & 1 & 0.1886 \\
\hline$B$-Percentage of plasticizer & 83.20 & 83.20 & -2.15 & 1.87 & 1 & 0.2687 \\
\hline C-pH of source phase & 73.29 & 73.29 & -2.02 & 1.87 & 1 & 0.2980 \\
\hline$D$-Receiving phase acid concentration & 100.58 & 100.58 & 2.36 & 1.87 & 1 & 0.2259 \\
\hline$A B$ & 10.34 & 10.34 & -0.80 & 1.99 & 1 & 0.6913 \\
\hline$A C$ & 4.75 & 4.75 & -0.55 & 1.99 & 1 & 0.7874 \\
\hline$A D$ & 6.71 & 6.71 & 0.65 & 1.99 & 1 & 0.7488 \\
\hline$B C$ & 3.55 & 3.55 & 0.47 & 1.99 & 1 & 0.8156 \\
\hline$B D$ & 3.05 & 3.05 & -0.44 & 1.99 & 1 & 0.8290 \\
\hline$C D$ & 2.56 & 2.56 & -0.40 & 1.99 & 1 & 0.8430 \\
\hline$A^{2}$ & $2,604.00$ & $2,604.00$ & -31.70 & 4.93 & 1 & $<0.0001$ \\
\hline$B^{2}$ & $1,751.12$ & $1,751.12$ & -26.00 & 4.93 & 1 & $<0.0001$ \\
\hline$C^{2}$ & 23.91 & 23.91 & -3.04 & 4.93 & 1 & 0.5473 \\
\hline$D^{2}$ & 35.04 & 35.04 & 3.68 & 4.93 & 1 & 0.4675 \\
\hline Residual & 945.87 & 63.06 & & & 15 & \\
\hline Total & $21,691.40$ & & & & 29 & \\
\hline Std. Dev. & 7.94 & & & & & \\
\hline$R^{2}$ & 0.9564 & & & & & \\
\hline $\operatorname{Adj}-R^{2}$ & 0.9157 & & & & & \\
\hline Pred- $R^{2}$ & 0.8497 & & & & & \\
\hline
\end{tabular}

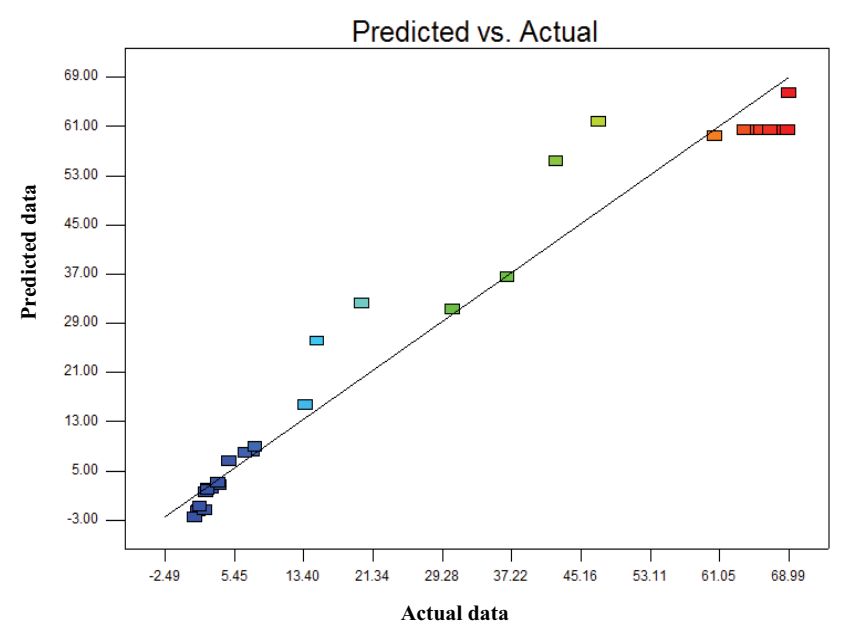

Fig. 6. Removal factor between actual and predicted values.

the squared effects, were all less than 0.05; consequently, the relation between each independent variable and the developed response was more curvature [43]. As can be expected, the designed approach has more accuracy than initial model (without the transformation function) to estimate the responses. Also, the dysfunctions have been eliminated and resulted in a reliable model, which can be considered as a general approach to predict the removal factor as following order (in terms of actual factors):

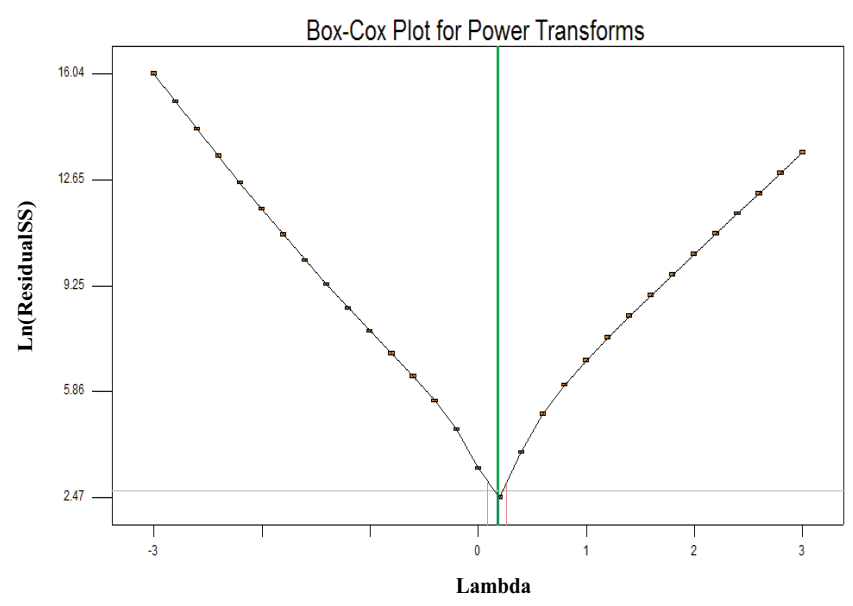

Fig. 7. Box-Cox plot for power transformations.

$$
\begin{gathered}
(\mathrm{RF})^{0.18}=-3.44+(0.082 A)+(0.153 B)+(0.195 C)+(0.251 D)- \\
\left(9.130 \times 10^{-5} A B\right)+\left(7.700 \times 10^{-4} A D\right)+\left(3.910 \times 10^{-4} B C\right)- \\
\left(1.771 \times 10^{-3} A^{2}\right)-\left(1.433 \times 10^{-3} B^{2}\right)-\left(0.027 C^{2}\right)-\left(0.065 D^{2}\right)
\end{gathered}
$$

The equation in terms of coded factors is also represented in Eq. (10): 
Table 5

ANOVA results for transformed model and modified quadratic equation of Design-Expert 7.0

\begin{tabular}{|c|c|c|c|c|c|c|}
\hline & \multicolumn{6}{|c|}{$\mathrm{Co}(\mathrm{II})$ removal factor $(\%)$} \\
\hline & $\begin{array}{l}\text { Sum of } \\
\text { squares }\end{array}$ & $\begin{array}{l}\text { Mean } \\
\text { squares }\end{array}$ & $\begin{array}{l}\text { Coded } \\
\text { coefficient }\end{array}$ & $\begin{array}{l}\text { Standard } \\
\text { error }\end{array}$ & $\mathrm{df}$ & $p$-Value \\
\hline Model & 5.22 & 0.47 & 2.13 & $6.192 \mathrm{e}-003$ & 11 & $<0.0001$ \\
\hline$A$-Carrier percentage & 0.22 & 0.22 & 0.11 & $4.698 \mathrm{e}-003$ & 1 & $<0.0001$ \\
\hline$B$-Percentage of plasticizer & 0.10 & 0.10 & -0.075 & $4.698 \mathrm{e}-003$ & 1 & $<0.0001$ \\
\hline C-pH of source phase & 0.067 & 0.067 & -0.061 & $4.698 \mathrm{e}-003$ & 1 & $<0.0001$ \\
\hline$D$-Receiving phase acid concentration & 0.091 & 0.091 & 0.071 & $4.698 \mathrm{e}-003$ & 1 & $<0.0001$ \\
\hline$A B$ & $6.751 \mathrm{e}-003$ & $6.751 \mathrm{e}-003$ & -0.021 & $4.698 \mathrm{e}-003$ & 1 & 0.0006 \\
\hline$A D$ & $2.135 \mathrm{e}-003$ & $2.135 \mathrm{e}-003$ & 0.012 & $4.698 \mathrm{e}-003$ & 1 & 0.0324 \\
\hline$B C$ & $2.201 \mathrm{e}-003$ & $2.201 \mathrm{e}-003$ & 0.012 & 4.698e-003 & 1 & 0.0301 \\
\hline$A^{2}$ & 0.41 & 0.41 & -0.4 & 0.012 & 1 & $<0.0001$ \\
\hline$B^{2}$ & 0.27 & 0.27 & -0.32 & 0.012 & 1 & $<0.0001$ \\
\hline$C^{2}$ & 0.031 & 0.031 & -0.11 & 0.012 & 1 & $<0.0001$ \\
\hline$D^{2}$ & 0.011 & 0.011 & -0.065 & 0.012 & 1 & $<0.0001$ \\
\hline Residual & 7.151e-003 & $3.973 \mathrm{e}-004$ & & & 18 & - \\
\hline Total & 5.23 & & & & 29 & - \\
\hline Std. Dev. & 0.020 & & & & & \\
\hline$R^{2}$ & 0.9986 & & & & & \\
\hline $\mathrm{Adj}-R^{2}$ & 0.9978 & & & & & \\
\hline Pred- $R^{2}$ & 0.9954 & & & & & \\
\hline
\end{tabular}

$$
\begin{gathered}
(\mathrm{RF})^{0.18}=+2.13+(0.11 A)-(0.075 B)-(0.061 C)+(0.071 D)- \\
\quad(0.021 A B)+(0.012 A D)+(0.012 B C)-\left(0.40 A^{2}\right)- \\
\left(0.32 B^{2}\right)-\left(0.11 C^{2}\right)-\left(0.065 D^{2}\right)
\end{gathered}
$$

In aforementioned equations, $A, B, C$, and $D$ represent the carrier percentage, percentage of plasticizer, $\mathrm{pH}$ of source phase, and receiving phase acid concentration, respectively. The impact of variables on the removal factor can be interpreted based on the coded values. The coded equation indicates that the carrier percentage and receiving phase acid concentration have a positive effect on the removal factor. On the other hand, the percentage of plasticizer and $\mathrm{pH}$ of source phase showed a negative effect on the removal factor of $\mathrm{Co}(\mathrm{II})$ ions in the feed phase. It is worth mentioning that the carrier percentage has an effect about 1.5 times more than other independent variables. From the coded equation, the interaction effect of "carrier percentage/plasticizer percentage" has a negative role on the removal factor. On the contrary, the interaction effect of "carrier percentage/receiving phase acid concentration" and the "concentration of plasticizer/pH of source phase" have a positive impact on the removal factor. All interaction effects on the Co(II) removal are not as significant as individual parameters or squared effects. Also, it should be noted that all squared effects have negative impacts, and the highest one is related to the carrier percentage, followed by the percentage of plasticizer and $\mathrm{pH}$ of source phase [44].

The predicted vs. actual data plot is shown in Fig. 8 . As can be observed, all experimental tests are fully close to $y=x$ line, which shows an excellent agreement between the

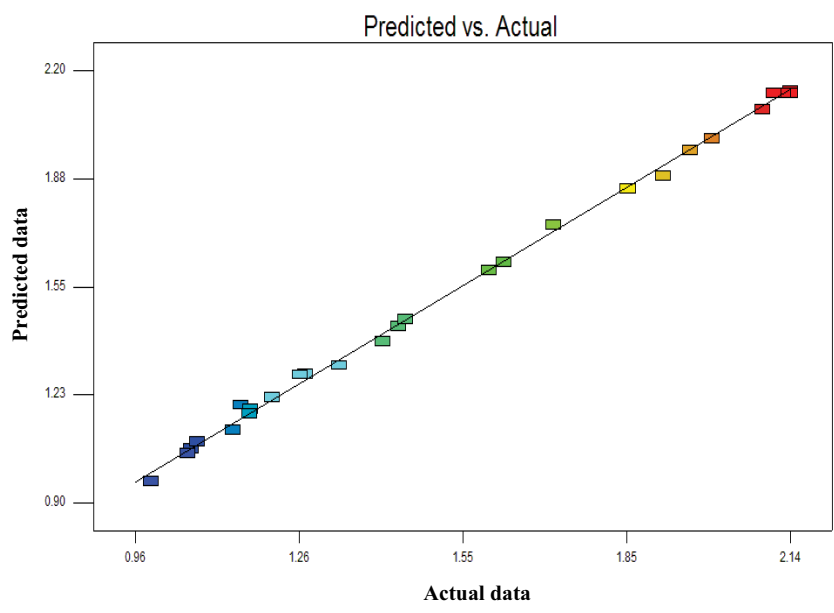

Fig. 8. Predicted vs. actual responses plot for Co(II) removal modeling by transformation and modified quadratic model.

experimental and predicted values. In this way, the validity of developed model for prediction of the removal factor is properly confirmed [43].

A comparison between the precise values of the predicted and the experimental data is represented in Fig. 9. As shown, there is a negligible error between these values at 30 different experimental conditions.

The results of modified quadratic model represent 0.9986 and 0.9978 for $R^{2}$ and $\mathrm{Adj}-R^{2}$, respectively; which indicate the high accuracy of the developed approach for prediction of the considered response. The value of $R^{2}$ specifies that only 


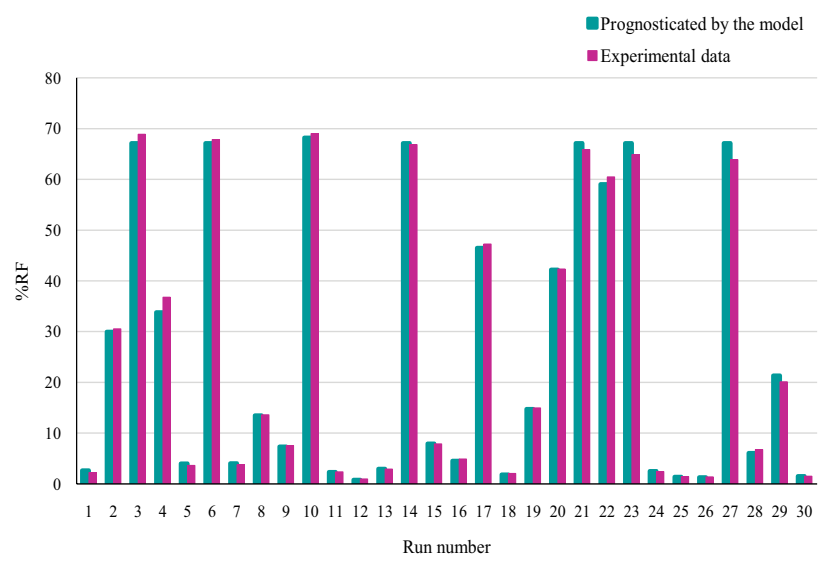

Fig. 9. Predicted and actual values at 30 different proposed conditions by the RSM.

$0.14 \%$ of total variations has not been covered by the proposed model [45]. Also, the value of pred- $R^{2}(0.9954)$ is in a reasonable agreement with the $\mathrm{Adj}-R^{2}$ (0.9978). Furthermore, "Adeq. Precision" factor, which measures the signal to noise ratio was 93.27 (much higher than 4), indicates a promising response [45].

\subsection{Effect of independent parameters}

The interaction effects between considered parameters by means of 3D plots and 2D contours are represented in Figs. 10-12. The impact of carrier percentage and percentage of plasticizer on the removal factor has been demonstrated in Fig. 10; by considering the constant values of 4.5 and $1.5 \mathrm{~mol} \mathrm{~L}^{-1}$ for the $\mathrm{pH}$ of source phase and receiving phase acid concentration, respectively.

The circular contour in Fig. $10 \mathrm{~b}$ indicates the interaction between the carrier percentage and the percentage of plasticizer is negligible [46]. Also, as shown in Fig. 10a, the removal factor enhances by increasing the carrier percentage and percentage of plasticizer. There is a maximum value for removal factor $(69.40 \%)$ in which, further increment of these two parameters, contribute to the reduction of the removal factor. From the literature [47], as the carrier weight composition increases in the PIM, there is more carrier-ion complexes formed at the membrane surface; hence, the driving force for the ion transport raises, consequently, it results in more $\mathrm{Co}$ (II) removal [47]. But, beyond the $\sim 22.5 \%$ wt of the carrier, the removal factor decreases due to the enhancement of viscosity and thickness of the PIM by limiting the ion/ carrier complex diffusion through the membrane [15,47]. On the other hand, a PIM with higher percentage of plasticizer is a more flexible membrane, in which, the complexes can diffuse easier. Thus, a higher removal factor is observed until $\sim 53 \%$ wt of the plasticizer (as shown in Fig. 10a). It is worth mentioning that the increase of plasticizer percentage adversely affects the membrane thickness and viscosity $[47,48]$. Hence, the removal factor is reduced after the $\sim 53 \%$ wt of the plasticizer percentage.

The effect of the carrier percentage and receiving phase acid concentration on the removal factor is represented in Fig. 11. Here, the percentage of plasticizer and $\mathrm{pH}$ of source phase were considered at the constant values of $55 \%$ wt and 4.5 , respectively. As can be observed in Fig. 11b, the elliptical contour indicates that the interaction of the carrier percentage and receiving phase acid concentration is significant [49]. Figs. 11a and b demonstrate a slight increase in the removal factor by increasing the receiving phase acid concentration from 0.5 to $1.5 \mathrm{M}$. Also, it can be observed that beyond $1.5 \mathrm{M}$, the removal factor has no significant increment and it can be considered as a constant value. It is worth mentioning that a higher concentration of $\mathrm{H}_{2} \mathrm{SO}_{4}$ in the receiving phase contributes to a bigger driving force to transport ions through the PIM (according to Eq. (1)).

The effects of $\mathrm{pH}$ of source phase and percentage of plasticizer at the constant values of carrier percentage (20\%wt) and receiving phase acid concentration $(1.5 \mathrm{M})$ are evaluated in Fig. 12. As can be observed in Fig. 12a, the removal factor vs. $\mathrm{pH}$ of source phase has a similar
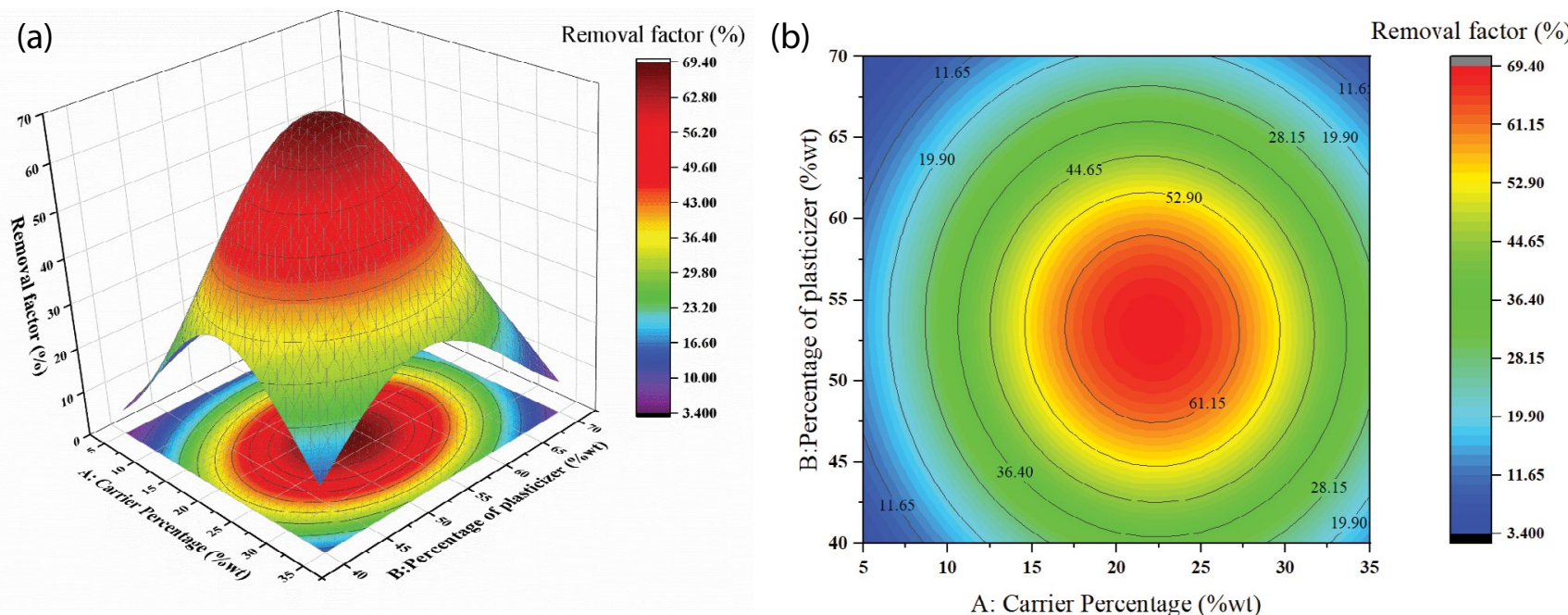

Fig. 10. (a) Response surface plots (2D) and (b) Contour plots (2D) showing the interaction effect of carrier percentage and percentage of plasticizer on $\%$ RF. 

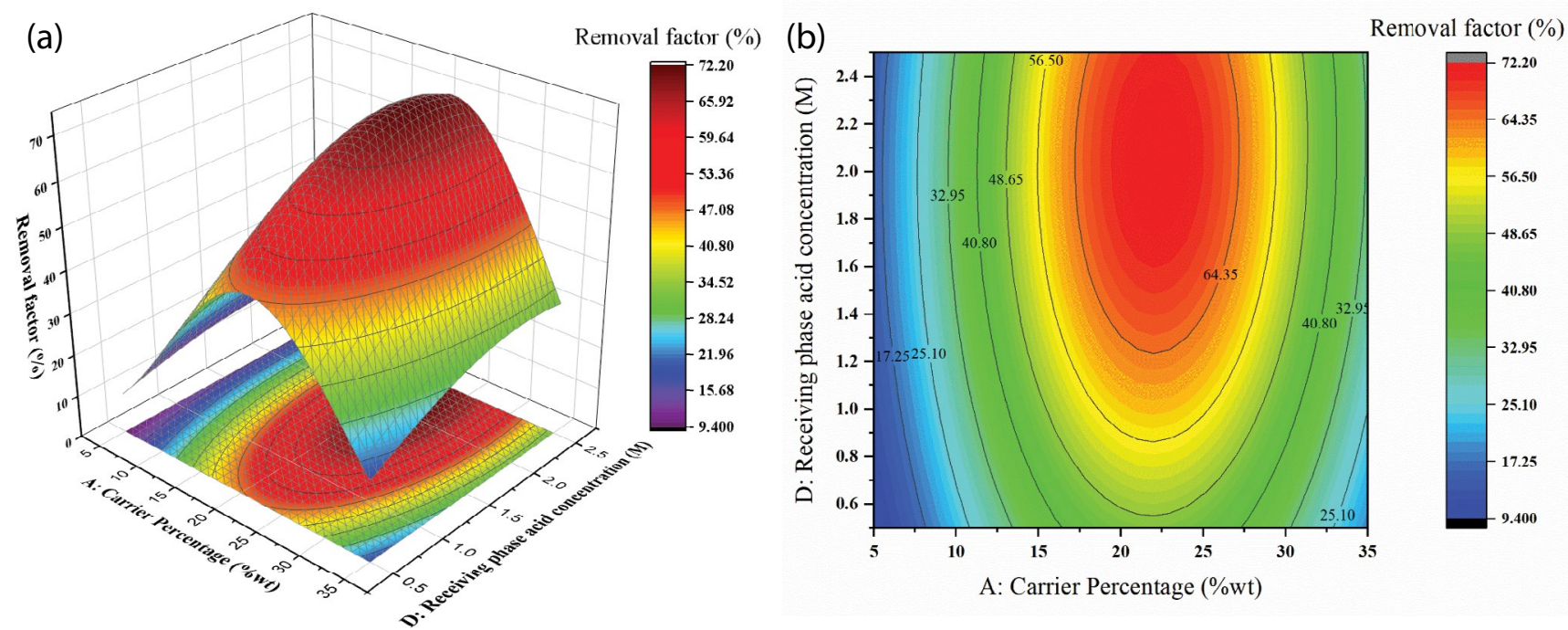

Fig. 11. (a) Response surface plots (3D) and (b) Contour plots (2D) showing the interaction effect of carrier percentage and receiving phase acid concentration \%RF.
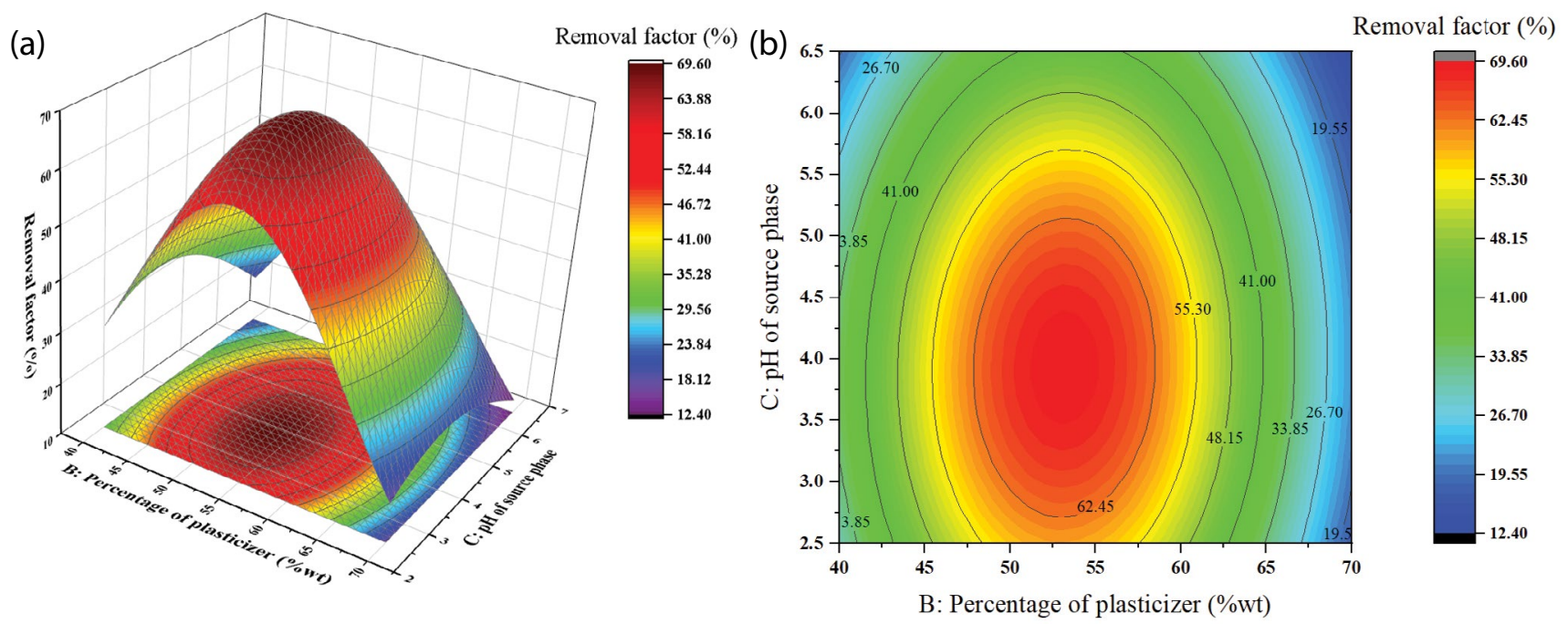

Fig. 12. (a) Response surface plots (3D) and (b) Contour plots (2D) showing the interaction effect of percentage of plasticizer and pH of source phase on removal factor $\%$ RF.

behavior with Fig. 10a and Fig. 11a. The removal factor increases till around $\mathrm{pH}=4$, and beyond this value, the $\mathrm{RF}$ decreases. On the other hand, the percentage of plasticizer has a similar impact on the RF. In this way, by increasing the percentage of plasticizer till $53.05 \% w t$, the RF grows to $69.60 \%$, after that, the RF decreases. The $2 \mathrm{D}$ contour in Fig. $12 \mathrm{~b}$ confirms that the considered independent parameters vs. RF has a maximum value. In Fig. 12b, the elliptical contour proves the significant interactions between the percentage of plasticizer and $\mathrm{pH}$ of source phase [49]. As previously mentioned, according to Eq. (1), the increase of $\mathrm{pH}$ of source phase is desirable for constitution of ion/ carrier complex, which enhances the complex concentration at the membrane surface. In addition, the complex concentration difference along the membrane phase favors the diffusion of the complex through the membrane phase. Beyond the maximum RF point, the RF reduces due to the lower complex diffusion rate through the membrane [50]. Also, the complex formation increases with higher $\mathrm{pH}$ of the source phase and boosts the Co(II) removal process positively. On the other hand, high quantity of complexes faces low effective area for diffusion in the saturated membrane. Hence, the negative impact of higher $\mathrm{pH}$ overcomes the higher rate of complex formation at the source phase interface and the removal efficiency decreases [21,51].

\subsection{Optimization of Co(II) removal factor}

In the last part of this work, the most efficient operating conditions in which, the RF is maximum, was calculated 
Table 6

30 experiments for finding the most efficient point in $\mathrm{Co}(\mathrm{II})$ removal process

\begin{tabular}{|c|c|c|c|c|c|}
\hline $\begin{array}{l}\text { Solution } \\
\text { number }\end{array}$ & $\begin{array}{l}\text { Carrier } \\
\text { percentage }(\% w t)\end{array}$ & $\begin{array}{l}\text { Percentage of } \\
\text { plasticizer }(\% w t)\end{array}$ & $\begin{array}{l}\mathrm{pH} \text { of source } \\
\text { phase }\end{array}$ & $\begin{array}{l}\text { Receiving phase acid } \\
\text { concentration }\left(\mathrm{mol} \mathrm{L}^{-1}\right)\end{array}$ & $\begin{array}{l}\text { Removal } \\
\text { factor (\%) }\end{array}$ \\
\hline 1 & 24.22 & 52.58 & 3.16 & 2.40 & 69.12 \\
\hline 2 & 23.10 & 54.30 & 4.22 & 2.26 & 73.25 \\
\hline 3 & 21.90 & 54.13 & 4.06 & 1.51 & 70.76 \\
\hline 4 & 22.95 & 49.41 & 4.26 & 1.77 & 69.29 \\
\hline 5 & 22.61 & 51.96 & 4.31 & 2.27 & 73.04 \\
\hline 6 & 23.26 & 54.14 & 3.43 & 1.58 & 69.95 \\
\hline 7 & 23.03 & 54.30 & 4.32 & 1.63 & 71.10 \\
\hline 8 & 23.67 & 51.85 & 4.70 & 2.42 & 69.12 \\
\hline 9 & 20.48 & 51.56 & 4.67 & 1.83 & 69.56 \\
\hline 10 & 23.23 & 54.41 & 3.48 & 1.81 & 72.11 \\
\hline 11 & 21.24 & 56.18 & 3.40 & 2.24 & 70.00 \\
\hline 12 & 21.94 & 52.97 & 3.01 & 2.40 & 69.04 \\
\hline 13 & 22.77 & 54.27 & 4.51 & 2.37 & 71.48 \\
\hline 14 & 23.08 & 49.53 & 3.71 & 1.70 & 69.39 \\
\hline 15 & 25.50 & 52.85 & 3.44 & 2.15 & 70.00 \\
\hline 16 & 22.86 & 55.43 & 3.75 & 1.58 & 70.12 \\
\hline 17 & 19.05 & 55.83 & 3.81 & 2.11 & 69.44 \\
\hline 18 & 23.91 & 56.50 & 4.37 & 2.23 & 69.53 \\
\hline 19 & 20.78 & 55.06 & 3.38 & 2.04 & 71.45 \\
\hline 20 & 22.91 & 52.13 & 3.33 & 1.59 & 69.90 \\
\hline 21 & 21.80 & 53.99 & 3.24 & 2.02 & 71.99 \\
\hline 22 & 21.47 & 54.98 & 3.33 & 2.04 & 71.73 \\
\hline 23 & 23.20 & 54.75 & 3.88 & 1.61 & 71.20 \\
\hline 24 & 24.61 & 53.62 & 3.69 & 1.81 & 71.66 \\
\hline 25 & 21.12 & 52.77 & 4.58 & 1.69 & 70.55 \\
\hline 26 & 23.96 & 54.66 & 3.76 & 2.30 & 72.26 \\
\hline 27 & 21.07 & 52.04 & 3.38 & 1.59 & 69.89 \\
\hline 28 & 20.45 & 51.55 & 3.15 & 1.93 & 69.80 \\
\hline 29 & 20.76 & 51.11 & 4.67 & 2.22 & 69.68 \\
\hline 30 & 23.54 & 53.69 & 3.61 & 1.82 & 72.78 \\
\hline
\end{tabular}

${ }^{a}$ The percentages of carrier and plasticizer have been considered based on the reference membrane $(0.1211 \mathrm{~g}$ CTA, $0.3263 \mathrm{~g}$ DOA, and $0.0789 \mathrm{~g}$ DNNSA). The reference membrane total weight was $0.5263 \mathrm{~g}$, which was the considered reference for calculation of carrier and plasticizer percentage.

by RSM via Design-Expert 7.0. The objective function was defined to maximize the RF in this process; hence, the response was set at "Maximized" and the independent variables were set "In range". Thirty experiments were designed by the software to find the most efficient point, in which the removal factor is maximized (Table 6). The optimum value, which is the program's output for the independent variables were $23.10 \%$ wt of the carrier percentage and $54.30 \%$ wt of the percentage of plasticizer. Also, the $\mathrm{pH}$ of the source phase equals to 4.22 , and receiving phase acid concentration is $2.26 \mathrm{M}$. The calculated RF at the optimum conditions was $73.25 \%$. Then, an experimental test was performed at the obtained optimum factors to investigate the reliability of the optimization procedure, which the result of this experiment was $73.99 \%$ after $24 \mathrm{~h}$. It can clearly be observed that only $1.01 \%$ error exists between the predicted and experimental values, which proves the accuracy and reliability of developed model.

\section{Conclusions}

In this study, the effects of two parameters of membrane compositions and two aqueous phase parameters were investigated using the RSM via CCD model. In this way, a modified quadratic model with power transformation $(\lambda=0.18)$ was applied to develop an accurate correlation between the response and considered independent variables (carrier percentage, percentage of plasticizer, $\mathrm{pH}$ of source phase, and receiving phase acid concentration). It was observed that the interaction between the variables were "carrier percentage/receiving phase acid concentration" > "percentage of plasticizer/pH of source 
phase" $^{\text {> }}$ "carrier percentage/percentage of plasticizer". Also, the optimized model represented the optimum condition of $23.10 \% \mathrm{wt}$ for the carrier percentage, $54.30 \% \mathrm{wt}$ of the percentage of plasticizer, 4.22 of $\mathrm{pH}$ of the source phase, and $2.26 \mathrm{M}$ of the receiving phase acid concentration. In addition, the reliability of the optimized values was tested by studying the optimal conditions, experimentally. The error of $1.01 \%$ proved that the proposed model is fully reliable and can be considered as a general approach to estimate the RF behavior vs. four studied variables. Finally, it was demonstrated that the RSM has an excellent ability to investigate the performance of the PIM by considering the main factors of the purification process.

\section{References}

[1] P. Munnik, P.E. De Jongh, K.P. De Jong, Control and impact of the nanoscale distribution of supported cobalt particles used in Fischer-Tropsch catalysis, J. Am. Chem. Soc., 136 (2014) 7333-7340.

[2] G.Z. Kyzas, E.A. Deliyanni, K.A. Matis, Activated carbons produced by pyrolysis of waste potato peels: cobalt ions removal by adsorption, Colloids Surf., A, 490 (2016) 74-83.

[3] X. Li, Z. Lei, J. Qu, Z. Li, Q. Zhang, Separation of copper from cobalt in sulphate solutions by using $\mathrm{CaCO}_{3}$, Sep. Sci. Technol., 51 (2016) 2772-2779.

[4] A. Rahmaninia, Y. Mansoori, F. Nasiri, Surface-initiated atom transfer radical polymerization of a new rhodanine-based monomer for rapid magnetic removal of Co (II) ions from aqueous solutions, Polym. Adv. Technol., 29 (2018) 1988-2001.

[5] T. Anirudhan, J. Deepa, J. Christa, Nanocellulose/nanobentonite composite anchored with multi-carboxyl functional groups as an adsorbent for the effective removal of Cobalt (II) from nuclear industry wastewater samples, J. Colloid Interface Sci., 467 (2016) 307-320.

[6] C.A. Kozlowski, W. Walkowiak, Competetive transport of cobalt-60, strontium-90, and cesium-137 radioisotopes across polymer inclusion membranes with DNNS, J. Membr. Sci., 297 (2007) 181-189.

[7] F. Fang, L. Kong, J. Huang, S. Wu, K. Zhang, X. Wang, B. Sun, Z. Jin, J. Wang, X.-J. Huang, Removal of cobalt ions from aqueous solution by an amination graphene oxide nanocomposite, J. Hazard. Mater., 270 (2014) 1-10.

[8] M. Abbas, S. Kaddour, M. Trari, Kinetic and equilibrium studies of cobalt adsorption on apricot stone activated carbon, J. Ind. Eng. Chem., 20 (2014) 745-751.

[9] D. Imessaoudene, S. Hanini, A. Bouzidi, A. Ararem, Kinetic and thermodynamic study of cobalt adsorption by spent coffee, Desal. Wat. Treat., 57 (2016) 6116-6123.

[10] Y. Yildiz, A. Manzak, O. Tutkun, Selective extraction of cobalt ions through polymer inclusion membrane containing Aliquat 336 as a carrier, Desal. Wat. Treat., 57 (2016) 4616-4623.

[11] S.S. Foltova, T. Vander Hoogerstraete, D. Banerjee, K. Binnemans, Samarium/cobalt separation by solvent extraction with undiluted quaternary ammonium ionic liquids, Sep. Purif. Technol., 210 (2019) 209-218.

[12] B. Swain, H.-W. Shim, C.G. Lee, Extraction/separations of cobalt by supported liquid membrane: a review, Korean Chem. Eng. Res., 57 (2019) 313-320.

[13] F. Kubota, R. Kono, W. Yoshida, M. Sharaf, S.D. Kolev, M. Goto, Recovery of gold ions from discarded mobile phone leachate by solvent extraction and polymer inclusion membrane (PIM) based separation using an amic acid extractant, Sep. Purif. Technol., 214 (2019) 156-161.

[14] R. Vera, E. Anticó, J.I. Eguiazábal, N. Aranburu, C. Fontàs, First report on a solvent-free preparation of polymer inclusion membranes with an ionic liquid, Molecules, 24 (2019) 1845.

[15] A. Kaya, C. Onac, H.K. Alpoguz, A. Yilmaz, N. Atar, Removal of $\mathrm{Cr}$ (VI) through calixarene based polymer inclusion membrane from chrome plating bath water, Chem. Eng. J., 283 (2016) 141-149.

[16] C.F. Croft, M.I.G. Almeida, R.W. Cattrall, S.D. Kolev, Separation of lanthanum (III), gadolinium (III) and ytterbium (III) from sulfuric acid solutions by using a polymer inclusion membrane, J. Membr. Sci., 545 (2018) 259-265.

[17] D.A. Fadel, L.A. Shouman, R.M. Afify, Selective transport of chromium (III), cobalt (II), barium (II) and strontium (II) ions through polymer inclusion membranes, Desal. Wat. Treat., 103 (2018) 163-174.

[18] B. Mahanty, P.K. Mohapatra, D. Raut, D. Das, P. Behere, M. Afzal, Polymer inclusion membranes containing $N, N, N^{\prime}$, $\mathrm{N}^{\prime}$-tetra (2-ethylhexyl) diglycolamide: uptake isotherm and actinide ion transport studies, Ind. Eng. Chem. Res., 54 (2015) 3237-3246.

[19] M. Vázquez, V. Romero, C. Fontàs, E. Anticó, J. Benavente, Polymer inclusion membranes (PIMs) with the ionic liquid (IL) Aliquat 336 as extractant: effect of base polymer and IL concentration on their physical-chemical and elastic characteristics, J. Membr. Sci., 455 (2014) 312-319.

[20] E.R. de San Miguel, J.C. Aguilar, J. de Gyves, Structural effects on metal ion migration across polymer inclusion membranes: dependence of transport profiles on nature of active plasticizer, J. Membr. Sci., 307 (2008) 105-116.

[21] N. Kavitha, K. Palanivelu, Recovery of copper (II) through polymer inclusion membrane with di (2-ethylhexyl) phosphoric acid as carrier from e-waste, J. Membr. Sci., 415 (2012) 663-669.

[22] N. Benosmane, B. Boutemeur, S.M. Hamdi, M. Hamdi, Removal of phenol from aqueous solution using polymer inclusion membrane based on mixture of CTA and CA, Appl. Water Sci., 8 (2018) 17.

[23] A. Tor, G. Arslan, H. Muslu, A. Celiktas, Y. Cengeloglu, M. Ersoz, Facilitated transport of $\mathrm{Cr}$ (III) through polymer inclusion membrane with di (2-ethylhexyl) phosphoric acid (DEHPA), J. Membr. Sci., 329 (2009) 169-174.

[24] M. Shirzad, M. Karimi, H. Abolghasemi, Polymer inclusion membranes with dinonylnaphthalene sulfonic acid as ion carrier for Co (II) transport from model solutions, Desal. Wat. Treat., 144 (2019) 185-200.

[25] A. Kaya, C. Onac, H.K. Alpoğuz, S. Agarwal, V.K. Gupta, N. Atar, A. Yilmaz, Reduced graphene oxide based a novel polymer inclusion membrane: transport studies of $\mathrm{Cr}$ (VI), J. Mol. Liq., 219 (2016) 1124-1130.

[26] S. García, M. Gil, C. Martín, J. Pis, F. Rubiera, C. Pevida, Breakthrough adsorption study of a commercial activated carbon for pre-combustion $\mathrm{CO}_{2}$ capture, Chem. Eng. J., 171 (2011) 549-556.

[27] A. Witek-Krowiak, K. Chojnacka, D. Podstawczyk, A. Dawiec, K. Pokomeda, Application of response surface methodology and artificial neural network methods in modelling and optimization of biosorption process, Bioresour. Technol., 160 (2014) 150-160.

[28] A. Ahmadi, S. Heidarzadeh, A.R. Mokhtari, E. Darezereshki, H.A. Harouni, Optimization of heavy metal removal from aqueous solutions by maghemite $\left(\gamma-\mathrm{Fe}_{2} \mathrm{O}_{3}\right)$ nanoparticles using response surface methodology, J. Geochem. Explor., 147 (2014) 151-158.

[29] S.K. Behera, H. Meena, S. Chakraborty, B. Meikap, Application of response surface methodology (RSM) for optimization of leaching parameters for ash reduction from low-grade coal, Int. J. Min. Sci. Technol., 28 (2018) 621-629.

[30] M. Karimi, J.A.C. Silva, C.N.d.P. Gonçalves, J.L. Diaz de Tuesta, A.E. Rodrigues, H.T. Gomes, $\mathrm{CO}_{2}$ capture in chemically and thermally modified activated carbons using breakthrough measurements: experimental and modeling study, Ind. Eng. Chem. Res., 57 (2018) 11154-11166.

[31] I. Zawierucha, C. Kozlowski, G. Malina, Removal of toxic metal ions from landfill leachate by complementary sorption and transport across polymer inclusion membranes, Waste Manage., 33 (2013) 2129-2136.

[32] D.W. Green, R.H. Perry, Perry's Chemical Engineers' Handbook/ edición Don W. Green y Robert H. Perry, 1973. 
[33] E. Radzyminska-Lenarcik, M. Ulewicz, The use of the steric effect of the carrier molecule in the polymer inclusion membranes for the separation of cobalt (II), nickel (II), copper (II), and zinc (II) ions, Pol. J. Chem. Technol., 17 (2015) 51-56.

[34] C. Onaç, A. Kaya, H. Alpoğuz, M. Yola, S. Eriskin, N. Atar, I. Şener, Recovery of Cr (VI) by using a novel calix [4] arene polymeric membrane with modified graphene quantum dots, Int. J. Environ. Sci. Technol., 14 (2017) 2423-2434.

[35] S. Yi, Y. Su, B. Qi, Z. Su, Y. Wan, Application of response surface methodology and central composite rotatable design in optimizing the preparation conditions of vinyltriethoxysilane modified silicalite/polydimethylsiloxane hybrid pervaporation membranes, Sep. Purif. Technol., 71 (2010) 252-262.

[36] T. Keskin Gündoğdu, İ. Deniz, G. Çalışkan, E.S. Şahin, N. Azbar, Experimental design methods for bioengineering applications, Crit. Rev. Biotechnol., 36 (2016) 368-388.

[37] M. Ghanbari, A. Hadian, A. Nourbakhsh, K. MacKenzie, Modeling and optimization of compressive strength and bulk density of metakaolin-based geopolymer using central composite design: a numerical and experimental study, Ceram. Int., 43 (2017) 324-335.

[38] J. Zolgharnein, A. Shahmoradi, J.B. Ghasemi, Comparative study of Box-Behnken, central composite, and Doehlert matrix for multivariate optimization of $\mathrm{Pb}$ (II) adsorption onto Robinia tree leaves, J. Chemom., 27 (2013) 12-20.

[39] T.Z.E. Lee, C. Krongchai, N.A.L.M.I. Lu, S. Kittiwachana, S.F. Sim, Application of central composite design for optimization of the removal of humic substances using coconut copra, Int. J. Ind. Chem., 6 (2015) 185-191.

[40] M. Ghaedi, H. Mazaheri, S. Khodadoust, S. Hajati, M. Purkait, Application of central composite design for simultaneous removal of methylene blue and $\mathrm{Pb}^{2+}$ ions by walnut wood activated carbon, Spectrochim. Acta, Part A, 135 (2015) 479-490.

[41] R.G. Brereton, Chemometrics: Data Analysis for the Laboratory and Chemical Plant, John Wiley \& Sons, 2003.

[42] M.S. Bhatti, A.S. Reddy, A.K. Thukral, Electrocoagulation removal of $\mathrm{Cr}$ (VI) from simulated wastewater using response surface methodology, J. Hazard. Mater., 172 (2009) 839-846.
[43] M. Aliabadi, M. Irani, J. Ismaeili, S. Najafzadeh, Design and evaluation of chitosan/hydroxyapatite composite nanofiber membrane for the removal of heavy metal ions from aqueous solution, J. Taiwan Inst. Chem. Eng., 45 (2014) 518-526.

[44] P. Sharma, B.K. Bajaj, Production of poly- $\beta$-hydroxybutyrate by Bacillus cereus PS 10 using biphasic-acid-pretreated rice straw, Int. J. Biol. Macromol., 79 (2015) 704-710.

[45] R. Mohammadi, M.A. Mohammadifar, A.M. Mortazavian, M. Rouhi, J.B. Ghasemi, Z. Delshadian, Extraction optimization of pepsin-soluble collagen from eggshell membrane by response surface methodology (RSM), Food Chem., 190 (2016) 186-193.

[46] A. Zainoodin, S.K. Kamarudin, M. Masdar, W.R.W. Daud, A.B. Mohamad, J. Sahari, Optimization of a porous carbon nanofiber layer for the membrane electrode assembly in DMFC, Energy Convers. Manage., 101 (2015) 525-531.

[47] C. Onac, H.K. Alpoguz, E. Akceylan, M. Yilmaz, Facilitated transport of $\mathrm{Cr}$ (VI) through polymer inclusion membrane system containing calix [4] arene derivative as carrier agent, J. Macromol. Sci. Part A, 50 (2013) 1013-1021.

[48] S.D. Kolev, A.M. St John, R.W. Cattrall, Mathematical modeling of the extraction of uranium (VI) into a polymer inclusion membrane composed of PVC and di-(2-ethylhexyl) phosphoric acid, J. Membr. Sci., 425 (2013) 169-175.

[49] C. Dong, J. Chen, Optimization of process parameters for anaerobic fermentation of corn stalk based on least squares support vector machine, Bioresour. Technol., 271 (2019) 174-181.

[50] X. Meng, Y. Song, Y. Lv, X. Xin, T. Ren, X. Wang, Study on stable mass transfer and enrichment of phenol by 1-octanol/kerosene/ polyvinyl chloride polymer inclusion membrane, Environ. Pollut., 253 (2019) 1100-1106.

[51] C.A. Kozlowski, W. Walkowiak, Removal of chromium (VI) from aqueous solutions by polymer inclusion membranes, Water Res., 36 (2002) 4870-4876. 


\begin{tabular}{|l|l|}
\hline \multicolumn{2}{|c|}{ Author Query } \\
\hline AQ1 & Please check the edits made to the order of the affiliation and confirm. \\
\hline AQ2 & $\begin{array}{l}\text { Should “Design Experiments" be changed to "Design of Experiments"? Please } \\
\text { suggest. }\end{array}$ \\
\hline AQ3 & Please check the sentence “While this strategy (RSM) has already..." for clarity. \\
\hline AQ4 & Please provide location details for reference [41]. \\
\hline AQ5 & Should "DNNS" be changed to "DNNSA" in the occurrences provided. \\
\hline
\end{tabular}

